Pesq. Vet. Bras. 37(8):813-819, agosto 2017 DOI: $10.1590 / \mathrm{S} 0100-736 \mathrm{X} 2017000800006$

\title{
Pesquisa de anticorpos IgG para Neospora caninum e avaliação dos fatores de risco em ovinos do Estado de Sergipe ${ }^{1}$
}

\author{
Huber Rizzo ${ }^{2 *}$, Taile K.S. de Jesus ${ }^{3}$, Natália C. Gaeta ${ }^{4}$, Jeferson S. Carvalho ${ }^{3}$, José W. \\ Pinheiro Júnior ${ }^{2}$, Lilian Gregory ${ }^{5}$,Solange M. Gennari ${ }^{6}$ e Eliana M.C. Villalobos ${ }^{7}$
}

\begin{abstract}
Rizzo H., De Jesus T.K.S., Gaeta N.C., Carvalho J.S., Pinheiro Júnior J.W., Gregory L., Gennari S.M. \& Villalobos E.M.C. 2017. [Neospora caninum IgG antibody research and evaluation of the risk factors associated to the infection in ovine, State of Sergipe, Brazil.] Pesquisa de anticorpos IgG anti-Neospora caninum e avaliação dos fatores de risco em ovinos do Estado de Sergipe. Pesquisa Veterinária Brasileira 37(8):813-819. Departamento de Medicina Veterinária, Universidade Federal Rural de Pernambuco, Campus Dois Irmãos, Rua Manoel de Medeiros s/n, Recife, PE 52171-900, Brazil. E-mail: hubervet@gmail.com

The aim of this study was to determine the occurrence of antibodies IgG against Neospora caninum and evaluate the risk factors associated with the infection in ovine herds, State of Sergipe, Brazil. Blood samples $(n=1200)$ were collected from sheep raised in 60 sheep run located in the three mesoregions of the State of Sergipe, between 2011 e 2012. Antibodies were investigated by Indirect Immunofluorescence Antibody Test of which cutoff point was 50 and positive samples were diluted in base 2 until the last positive titer. Data from 15 variables was obtained from questionnaires given to farmers. Absolute and relative frequencies were determined and the risk factors were analyzed by Pearson's Qui-Square test $(\mathrm{p} \leq 0,05)$. The occurrences of serum reactive sheep were $39.83 \%$ (478/1200). The occurrences of positive sheep and sheep run were 55.88\% (380/680) and 88.24\% (30/34) in the Eastern region; $21.42 \%(60 / 280)$ e $42.85 \%(6 / 14)$ in dry region and $15.83 \%(38 / 240)$ e $41.67 \%(5 / 12)$ in the backwoods respectively. Antibody titers ranged from $50(n=459)$, represented $96.02 \%$ (459/478) of seropositive samples to $6400(1 / 478)$. Among the significant variables in the multivariate analysis were considered risk factors for infection with $N$. caninum were, sheep run located in Eastern region $(\mathrm{p}=0.000, \mathrm{OR}=4.64, \mathrm{CI} 95 \%=3.36-6.41)$; standing and running water sources $(\mathrm{p}=0.000 \mathrm{OR}=2.03, \mathrm{CI} 95 \%=1.41-2.92)$, absence of quarantine $(\mathrm{p}=0.000$, $\mathrm{OR}=2.71, \mathrm{CI} 95 \%=2.08-3.53)$, absence of dunghill $(\mathrm{p}=0.000, \mathrm{OR}=3.14, \mathrm{CI} 95 \%=2.45-4.02)$, presence of dogs $(\mathrm{p}=0.000, \mathrm{OR}=2.74, \mathrm{CI} 95 \%=1.73-433)$, presence of wild animals $(\mathrm{p}=0.000$, $\mathrm{OR}=3.45, \mathrm{CI} 95 \%=2.44-4.87)$ and subsistence $(\mathrm{p}=0.000, \mathrm{OR}=4.99, \mathrm{CI} 95 \%=3.15-7.92)$ or reproduction $(\mathrm{p}=0.002, \mathrm{OR}=1.74, \mathrm{CI} 95 \%=1.22-2.49)$ livestock were important risk factors. Our results highlight the occurrence of $N$. caninum in the ovine herds from State of Sergipe. Management and location of sheep runs were important risk factors associated to the infection.

INDEX TERMS: Neospora caninum, infection, parasite, sheep, risk factors, indirect fluorescent antibody test.
\end{abstract}

\footnotetext{
${ }^{1}$ Recebido em 14 de janeiro de 2016.

Aceito para publicação em 13 de janeiro de 2017.

${ }^{2}$ Docente do Departamento de Medicina Veterinária (DMV), Universidade Federal Rural de Pernambuco (UFRPE), Campus Dois Irmãos, Rua Manoel de Medeiros s/n, Recife, PE 52171-900, Brasil.E-mail: wiltonjrufrpe@ gmail.com, *Autor para correspondência: hubervet@gmail.com

${ }^{3}$ Pós-Graduando do Programa de Pós-Graduação em Ciência Veterinária, DMV-UFRPE, Rua Manoel de Medeiros s/n, Recife, PE 52171-900, Brasil. E-mails: tailekatiele14@yahoo.com.br, jefersonsilvacarvalho@hotmail.com

${ }^{4}$ Pós-Graduanda do Programa de Pós-Graduação em Clínica Veterinária, Departamento de Clínica Médica (VCM), Faculdade de Medicina Veterinária e Zootecnia (FMVZ), Universidade de São Paulo (USP), Cidade Univer-
}

sitária, Av. Prof. Orlando Marques de Paiva 87, São Paulo, SP 05508-270, Brasil. E-mail: natalia.gaeta@hotmail.com

${ }^{5}$ Docente do Departamento de Clínica Médica (VCM), FMVZ-USP, Cidade Universitária, Av. Prof. Orlando Marques de Paiva 87, São Paulo, SP 05508270, Brasil. E-mail: lgregory@usp.br

${ }^{6}$ Docente do Departamento de Medicina Veterinária Preventiva e Saúde Animal (VPS), FMVZ-USP, Cidade Universitária, Av. Prof. Orlando Marques de Paiva 87, São Paulo, SP, 05508-270, Brasil. E-mail: sgennari@usp.br

${ }^{7}$ Pesquisadora do Laboratório de Raiva e Encefalites Viras, Centro de Pesquisa e Desenvolvimento de Sanidade Animal, Instituto Biológico de São Paulo, Av. Conselheiro Rodrigues Alves 1252, Moema, São Paulo, SP 04014-002, Brasil. E-mail: villalobos@biologico.sp.gov.br 
RESUMO.- 0 objetivo desse trabalho foi determinar a ocorrência de anticorpos IgG para Neospora caninum bem como avaliar os fatores de risco associados à infecção em rebanhos ovinos do estado de Sergipe, Brasil. Foram coletadas, nos anos de 2011 e 2012, 1200 amostras de sangue de ovinos oriundos de sessenta propriedades distribuídas em três mesorregiões do estado para pesquisa de anticorpos para N. caninum pela Reação de Imunofluorescência Indireta (RIFI) utilizando-se como ponto de corte de 50 e as amostras diluídas na base 2 . Os dados de 34 variáveis estudadas foram obtidos a partir de questionários aplicados aos proprietários e analisados para se determinar a frequências absolutas e relativas e análise dos fatores de risco pelo teste Qui-quadrado de Pearson $(p \leq 0,05)$. A ocorrência de ovinos soropositivos para $N$. caninum foi de 39,83\% (478/1200). Em relação às mesorregiões a ocorrência de animais e propriedades positivas foi de, respectivamente, $55,88 \%(380 / 680)$ e $88,24 \%(30 / 34)$ na Leste; $21,42 \%(60 / 280)$ e $42,85 \%$ (6/14) no Agreste e $15,83 \%(38 / 240)$ e $41,67 \%(5 / 12)$ no Sertão. Os títulos de anticorpos variaram de 50, representando $96,02 \%$ (459/478) das amostras soropositivas, a 6400 (1/478). Dentre as variáveis significantes, na analise multivariada, que foram consideradas com fatores de risco para a infecção pelo $N$. caninum estavam propriedades localizadas na mesorregião Leste $(\mathrm{p}=0,000, \mathrm{OR}=4,64, \mathrm{IC} 95 \%=3,36-6,41)$, presença de fonte de água parada e corrente $(\mathrm{p}=0,000$ $\mathrm{OR}=2,03$, IC95\%=1,41-2,92), ausência de quarentena ( $p=0,000$ OR=2,71, IC95\%=2,08-3,53), não utilização de esterqueiras ( $p=0,0000 R=3,14$, IC95\% $=2,45-4,02)$, criações com finalidade de subsistência $(\mathrm{p}=0,000 \mathrm{OR}=4,99$, IC95\%=3,15-7,92), de reprodução ( $\mathrm{p}=0,002, \mathrm{OR}=1,74$, IC95\%=1,22-2,49), presença de cães ( $\mathrm{p}=0,000 \mathrm{OR}=2,74$, IC95\%=1,73-433) e circulação de animais silvestres nos rebanhos ( $p=0,000$ OR=3,45, IC95\%=2,44-4,87). Os resultados evidenciam a ocorrência de $N$. caninum em rebanhos ovinos sergipanos, demonstrando o manejo e a localização dos rebanhos no estado como importantes fatores de risco.

TERMOS DE INDEXAÇÃO: Neospora caninum, infecção, parasita, ovelhas, fatores de risco, reação de imunofluorescência indireta.

\section{INTRODUÇÃO}

O estado de Sergipe possui um efetivo ovino de 187.129 mil cabeças, representando $2 \%$ do rebanho Nordestino, ainda assim a ovinocultura é uma atividade tradicional, com a presença de rebanhos formados principalmente por animais puros e mestiços da raça Santa Inês com alto valor zootécnico (Seagri 2015).

Doenças reprodutivas como brucelose, toxoplasmose, clamidiose, neosporose, dentre outras, estão entre as enfermidades que causam maiores prejuízos à produtividade em rebanhos ovinos (Forar et al. 1995). Na maioria das vezes, os problemas de ordem reprodutiva como retorno de cio, abortamentos, natimortalidade e infertilidade são os únicos e expressivos sinais de doença no rebanho. A suspeita diagnóstica para qualquer doença reprodutiva recai na observação do desempenho de produtividade do rebanho, juntamente com as informações clínicas (Aiello 2001).
Neospora caninum é um protozoário de parasitismo intracelular obrigatório, responsável pela formação de cistos em hospedeiros intermediários após a ingestão de oocistos eliminados por canídeos (Mugridge et al. 1999). A transmissão também pode ser vertical via transplacentária, que possui grande importância pois o animal clinicamente sadio se torna cronicamente infectado (Dubey \& Acland 1992). A infecção possui grande importância econômica, principalmente devido às perdas reprodutivas, incluindo retornos ao cio, com intervalos regulares ou irregulares, abortos, nascimento de animais fracos e inviáveis, com sinais neurológicos, ou persistentemente infectados (Dubey \& Lindsay 1996, Pinto et al. 2012).

Diversas variáveis estão inseridas como fatores de risco para a infecção de ovinos por $N$. caninum tais como o número de cães na propriedade, tamanho da propriedade, fonte da água fornecida ao rebanho, pastejo em áreas comuns a outras espécies animais, sistema de criação, condições climáticas, origem dos animais adquiridos, raça e supervisão veterinária (Al-Majali et al. 2008, Abo-Shehada \& Abu-Halaweh 2010, Faria et al. 2010, Machado et al. 2011, Rizzo et al. 2011, Paiz et al. 2015).

Levantamentos sorológicos para a detecção de anticorpos para $N$. caninum em ovinos no Brasil demonstram ampla ocorrência do agente, sendo registrado nas regiões Sul (Vogel et al. 2006, Romanelli et al. 2007, Pappen et al. 2008, Munhóz et al. 2010, Rosa et al. 2011, Moura et al 2014, Paiz et al. 2015), Sudeste (Figliuolo et al. 2004, Rossi et al. 2011, Langoni et al. 2010, Salaberry et al. 2010, Rizzo et al. 2011, Silva et al. 2011, Paiz et al. 2015), Centro Oeste (Oshiro et al. 2008, Ueno et al. 2009) e Norte (Aguiar et al. 2004), com ocorrência variando de 2,93 a 59,22\%.

Na região Nordeste estudos foram conduzidos nos estados da Bahia (Otero et al. 2005, Rocha et al. 2014), Pernambuco (Souza Neto et al. 2009, Tembue et al. 2011), Alagoas (Faria et al. 2010), Paraíba (Faria et al. 2007), Maranhão (Moraes et al. 2011), Piauí (Araújo et al. 2014) e Rio Grande do Norte (Soares et al. 2009). No estado do Sergipe há apenas um levantamento, do ano de 2008, no município de Tobias Barreto (D’Alencar et al. 2011). Deste modo, o presente trabalho teve por objetivo determinar a ocorrência de anticorpos IgG para $N$. caninum e avaliar os fatores de risco associados à infecção em rebanhos ovinos do estado de Sergipe, mediante a falta de informações publicadas.

\section{MATERIAL E MÉTODOS}

Os rebanhos ovinos utilizados nesse estudo eram criados no estado de Sergipe, região Nordeste do Brasil, que apresenta clima tropical no litoral e semiárido no interior. 0 estado tem na exploração pecuária umas de suas principais fontes de renda, sendo a ovinocultura, na maioria das vezes, uma atividade complementar à bovinocultura de corte (IBGE 2015, Seagri 2015). Possui uma área territorial de $21.918 .493 \mathrm{~km}^{2}$ dividida em três mesorregiões edafoclimáticas: Leste, Agreste e Sertão (Santos et al. 2014, IBGE 2015).

O cálculo amostral foi realizado conforme Thrusfield (1995), utilizando-se os seguintes parâmetros: população de 187.129 mil ovinos (IBGE 2013), nível de significância de 95\% e um percentual de margem do erro amostral de $5 \%$, utilizando a prevalência de $\pm 16,29 \%$, (Otero et al. 2005, Soares et al. 2009, Souza Neto et al. 2009, Faria et al. 2010, Moraes et al. 2011, Tembue et al. 2011), 


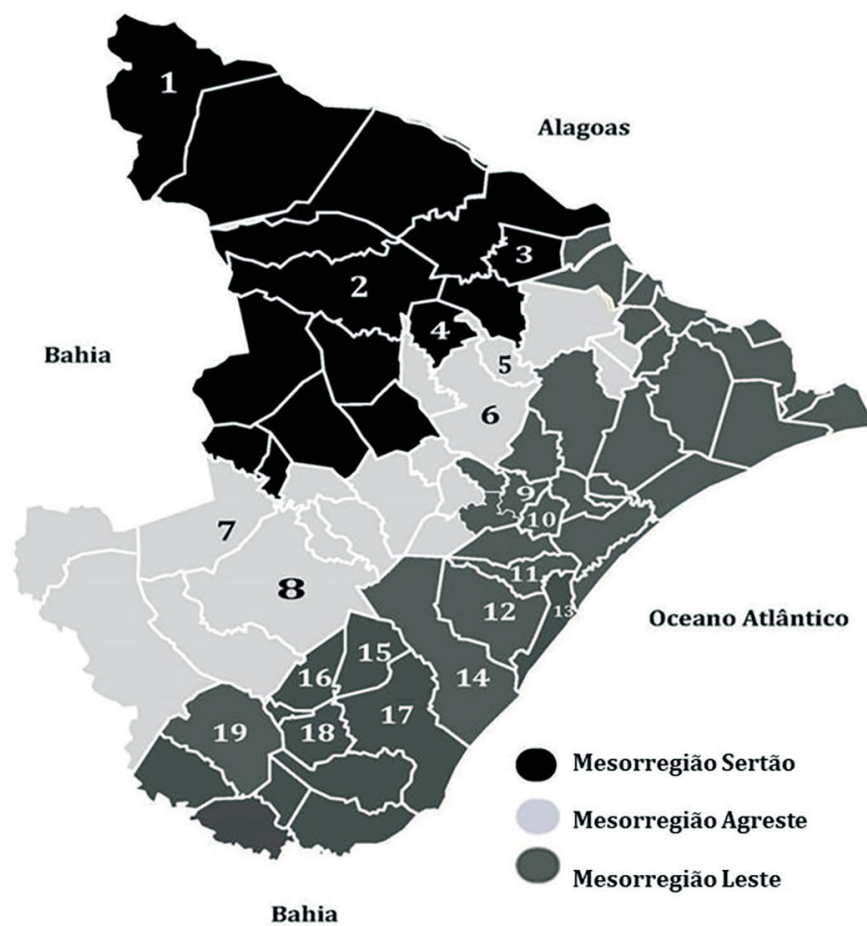

Fig.1. Mapa de Sergipe dividido entre suas três mesorregiões (Leste, Agreste e Sertão) demonstrando os munícipios de coleta para a pesquisa de anticorpos anti- $N$. caninum em ovinos, com numeração correspondente ao nome do município. Mesorregião Sertão: 1-Canindé de São Francisco, 2-Nossa Senhora da Glória, 3-Itabi e 4-Feira Nova; mesorregião Agreste: 5-Cumbe, 6-Nossa Senhora das Dores, 7-Simão Dias e 8-Lagarto; mesorregião Leste: 9-Divina Pastora, 10-Maruim, 11-Nossa Senhora do Socorro, 12-São Cristovão, 13-Aracaju, 14-Itaporanga D’ajuda, 15-Salgado, 16-Boquim, 17-Estância, 18-Arauá e 19-Itabaianinha (IBGE 2014).

resultando em amostragem mínima de 369 animais sendo 123 por mesorregião.

As amostras foram coletadas no período de março de 2011 a dezembro de 2012, totalizando 1.200 soros (990 de fêmeas e 210 de machos) oriundos de sessenta propriedades localizadas em dezenove municípios das três mesorregiões do estado: Leste, Agreste e Sertão (Figura 1) onde foi coletado, respectivamente, 680, 280 e 240. A escolha dos municípios e das propriedades foi realizada de acordo com a divisão do estado, conveniência, facilidade de acesso e disponibilidade dos produtores. Foram coletadas vinte amostras por propriedade, onde os animais testados foram selecionados aleatoriamente, sempre que possível na proporção de $80 \%$ de fêmeas e $20 \%$ de machos (reprodutores), entre diferentes padrões zootécnicos (raças puras, mestiços e sem raça definida), aparentemente saudáveis, com idade superior a seis meses. Em todas as propriedades visitadas, foi aplicado um questionário epidemiológico a fim de avaliar os fatores de risco associados à infecção por N. caninum, constituído de 34 questões fechadas, englobando as características do rebanho como: histórico, finalidade da criação, manejo sanitário, nutricional e reprodutivo, instalações e dados sobre o produtor.

As amostras de sangue foram coletadas por punção venosa, da veia jugular, em tubo a vácuo, sem anticoagulante, centrifugadas a 1600 g por 10 minutos, e os soros foram acondicionados em micro tubos e congelados a $-20^{\circ} \mathrm{C}$ até o momento da análise. 0 teste sorológico realizado foi a reação de imunofluorescência indireta (RIFI), utilizando como antígeno, para sensibilização das lâminas, taquizoítas da amostra de referência NC-1 mantidos em cultivo em células Vero em meio RPMI-1640 a 2\% de Soro Fetal Bovino (PBS). As lâminas foram secas em temperatura ambiente e em cada cavidade foi acrescido o conjugado de IgG ovino produzida em coelhos marcado com isotiocianato de fluoresceína (SIGMA ${ }^{\circledR}$ F7634) diluído com Azul de Evans 0,01\% e PBS (Camargo 1974). Em todas as lâminas foram usados controles positivos e negativos previamente conhecidos e para detecção de anticorpos para N. caninum utilizou-se títulos com ponto de corte 50 . As amostras positivas foram tituladas em diluições seriadas na base 2 (Figliuolo et al. 2004, Souza Neto et al. 2009, Munhóz et al. 2010, Rossi et al. 2011, Tembue et al. 2011).

A determinação das frequências absolutas e relativas foi obtida através da análise estatística descritiva. Para o estudo dos fatores de risco associados à infecção por $N$. caninum, foi realizada a análise univariada das variáveis de interesse pelo teste qui-quadrado de Pearson, ou Exato de Fisher, quando necessário. Posteriormente, foi realizada a análise de regressão logística considerando como variável dependente para a infecção por $N$. caninum o resultado da RIFI (positivo ou negativo). As variáveis independentes ou explanatórias consideradas no modelo foram aquelas que apresentaram significância estatística $<0,20$. Essa probabilidade foi estipulada para que possíveis fatores de risco do evento não fossem excluídos da análise (Hosmer \& Lemeshow 1989). O programa EpiInfo 3.5.1 foi utilizado para a execução dos cálculos estatísticos.

Todos os procedimentos utilizados nesse estudo foram aprovados pela Comissão de Bioética da Faculdade Pio Décimo, Aracaju, SE, protocolo número 06/2011.

\section{RESULTADOS E DISCUSSÃO}

A ocorrência de ovinos soropositivos a $N$. caninum nos sessenta rebanhos sergipanos estudados foi de 39,83\% (478/1200) (Quadro 1), valor mais baixo, entre os estudos nacionais, somente aos realizados nos municípios de Ibimirim, Pernambuco (Tembue et al. 2011) e Uberlândia, Minas Gerais, que estudou apenas dois rebanhos, (Rossi et al. 2011) com 64,20\% (52/81) e 47,09\% (73/155), respectivamente. Levantamento utilizando ovinos de abatedouros do estado de São Paulo e do Rio Grande do Sul apresentou 59,22\% (353/596) de soropositivos utilizando título de 1:25 como ponto de corte, menor que o adotado nos outros estudos (1:50), no entanto considerando somente os animais com titulação $\geq 50$ a ocorrência foi de 37,58\% (Paiz et al. 2015).

Na região Nordeste, onde o rebanho de ovinos é consideravelmente maior, as ocorrências observadas foram bem inferiores às do presente estudo. Otero et al. (2005) identificaram 7,45\% (21/282) de ovinos positivos na Bahia, Soares et al. (2009) 1,71\% (7/409) no Rio Grande Norte, Souza Neto et al. (2009) 10,12\% (16/158) em Pernambuco, Faria et al. (2010) 9,62\% (33/343) em Alagoas, Moraes et al. (2011) 4,69\% (3/64) no Maranhão, e Araújo et al. (2014) 5,13\% (8/156) no Piauí. Estas diferenças podem ocorrer devido características climáticas diversas que podem interferir no desenvolvimento e manutenção dos oocistos no ambiente. Rocha et al. (2014) observaram diferenças significativas entre propriedades de uma mesma região no sudeste da Bahia, com temperatura e umidade relativa diferentes.

Foi observado 68,33\% (41/60) de focos dentre as propriedades demonstrando que o agente etiológico está disseminado nos rebanhos ovinos sergipanos. Este valor está acima da média de estudos da região Nordeste realizados 
Quadro 4. Análise de regressão logística dos fatores de risco associados à infecção por $N$. caninum em ovinos, no estado de Sergipe 2011-2012

\begin{tabular}{lccc}
\hline \multicolumn{1}{c}{ Variável } & Valor de p & OR & IC 95\% \\
\hline Fonte de água parada e corrente & 0,000 & 2,03 & $1,41-2,92$ \\
Não utilizar esterqueira & 0,000 & 3,14 & $2,45-4,02$ \\
Não realizar quarentena & 0,000 & 2,71 & $2,08-3,53$ \\
Finalidade de criação (subsistência) & 0,000 & 4,99 & $3,15-7,92$ \\
Finalidade de criação (reprodução) & 0,002 & 1,74 & $1,22-2,49$ \\
Microrregião Leste & 0,000 & 4,64 & $3,36-6,41$ \\
Circulação de animais silvestres & 0,000 & 3,45 & $2,44-4,87$ \\
Presença de cães & 0,000 & 2,74 & $1,73-4,33$
\end{tabular}

tudadas para a infecção pelo $N$. caninum. A variável sexo $(p=0,295)$, não apresentou associação significativa com a positividade para $N$. caninum assim como relatado nos municípios de São Paulo/SP (Figliuolo et al. 2004), Guarapuava/PR (Romanelli et al. 2007), Mossoró/RN (Soares et al. 2009), Uberlândia/MG (Rossi et al. 2011) e no Distrito Federal (Ueno et al. 2009). Já Rizzo et al. (2011), em pesquisa no estado de São Paulo utilizando somente ovinos com histórico de problemas reprodutivos, relatou que ovelhas apresentaram 9,13 vezes mais chances de estarem infectados que carneiros.

No que diz respeito ao sistema de criação $(p=0,152)$, e disponibilização de ração $(\mathrm{p}=0,116)$, não houve significância nos valores obtidos, porém Souza Neto et al. (2009) trabalhando com rebanhos do município de Gravatá/PE, afirmaram que em regimes intensivos os índices elavam-se devido a maior concentração de animais ocorrendo maior exposição a alimentos contaminados. Terrenos alagados e acidentados, apesar da significância $(\mathrm{p}=0,000)$, não apresentaram associação com a infecção após análise da regressão logística, no entanto estes apresentam melhores condições para a esporulação e manutenção dos oocistos no ambiente (Corbelline et al. 2006). A mesma falta de associação foi observada em relação à animais com distúrbios reprodutivos ( $\mathrm{p}=0,000)$, assim como Moura et al. (2014) e diferindo dos achados de Rizzo et al. (2011), que obtiveram a associação com a repetição de cio, e de Munhóz et al. (2010).

A significância estatística observada na análise de regressão logística multivariada evidenciou como fatores de risco no estado estudado: localização com clima favorável ao desenvolvimento do agente, correspondente à mesorregião Leste ( $\mathrm{p}=0,000, \mathrm{OR}=4,64, \mathrm{IC} 95 \%=3,36-6,41)$, propriedades com presença de cães $(\mathrm{p}=0,000 \mathrm{OR}=2,74$, IC95\%=1,73-433), com circulação de animais silvestres ( $\mathrm{p}=0,000$ OR=3,45, IC95\%=2,44-4,87), de finalidade de criação de subsistência $(p=0,000 \quad O R=4,99$, IC95\% $=3,15$ $7,92)$, de reprodução $(p=0,002, O R=1,74$, IC $95 \%=1,22$ $2,49)$, fornecimento de água de fonte parada e corrente ( $\mathrm{p}=0,000 \mathrm{OR}=2,03$, IC95\%=1,41-2,92), além da não adoção do uso de esterqueira ( $\mathrm{p}=0,000$ OR=3,14, IC95\% $=2,45$ $4,02)$ e realização de quarentena $(p=0,000 \quad 0 R=2,71$, IC95\%=2,08-3,53), condições que indicam práticas de manejo higiênico-sanitárias deficientes elevando o risco de exposição ao patógeno (Gondim et al. 2005).

A associação da infecção com a mesorregião Leste do estado, se deu devido suas condições climáticas com maio- res índices pluviométricos e umidade relativa que as demais, favorecendo a esporulação dos oocistos (Wouda et al. 1999, Rocha et al. 2014). Em seis rebanhos do município sergipano de Tobias Barreto, localizado na mesorregião do Sertão, obteve-se 9,09\% (10/110) de ovinos soropositivos (D’Alencar et al. 2011), sendo essa mesorregião a de menor ocorrência no presente estudo, 15,83\% (38/240).

A maior ocorrência observada nos animais criados com finalidade de subsistência ( $p=0,000,0 R=4,99$, IC $95 \%=3,15$ $7,92)$ pode estar ligada ao fato das propriedades pertencerem a pequenos produtores, conhecidas como criações domésticas, nas quais as práticas de medidas sanitárias são inadequadas, na maioria das vezes favorecendo a exposição ao parasita. No caso das propriedades com finalidade de criação a reprodução ( $p=0,002,0 R=1,74$, IC $95 \%=1,22$ $2,49)$, ou seja, a criação de matrizes e reprodutores para a comercialização, a associação com a infecção pode estar relacionada com o tipo de criação mais intensiva (Souza Neto et al. 2009), principalmente com o uso de baias e piquetes coletivos.

Houve associação significativa entre a presença de cães $(\mathrm{p}=0,000,0 R=2,74$, IC95\%=1,73-433) e da circulação de animais silvestres ( $\mathrm{p}=0,000, \mathrm{OR}=3,45$, IC95\%=2,44-4,87) com o N. caninum. Segundo Al-Majali et al. (2008) a presença de um cão na propriedade, independente de estar infectado, é fator de risco para a neosporose em ovinos. Abo-Shehada \& Abu-Halaweh (2010) relataram que a alta prevalência de $N$. caninum em pequenos ruminantes, no Oriente Médio, deve-se a presença contínua dos cães junto aos rebanhos. Munhóz et al. (2010) observaram relação entre ovinos soropositivos e propriedades que realizavam o abate dos mesmos e permitiam, aos cães, acesso as vísceras, no entanto, o mesmo autor, assim como, Souza Neto et al. (2009), Figliuolo et al. (2004), Soares et al. (2009) e Rizzo et al. (2011) e Moura et al. (2014) não observaram associação entre presença de cães e ocorrência de anticorpos para $N$. caninum, sendo que alguns deles sugeriram que nas regiões estudadas a infecção poderia estar ocorrendo preferencialmente, pela via vertical. A presença dos hospedeiros definitivos, domésticos ou silvestres, que contaminem com suas fezes fontes de água parada ou nascentes de água correntes podem levar uma maior presença de ovinos soropositivos, no presente estudo o fornecimento de água de ambas as fontes ( $\mathrm{p}=0,000$, $\mathrm{OR}=2,03$, IC $95 \%=1,41-2,92$ ) se mostraram como fatores de risco.

\section{CONCLUSÃO}

Os resultados evidenciam a ocorrência de Neospora caninum em rebanhos ovinos sergipanos, demonstrando elevado número de animais soropositivos, associados principalmente a condições climáticas e práticas de manejo higiênico-sanitárias deficientes como a não adoção de esterqueiras e quarentena e a presença de hospedeiros definitivos do N. caninum.

Agradecimentos.- Ao Grupo de Iniciação Científica e Extensão em Buiatria (GICEB) da Faculdade Pio Décimo em Aracaju/SE pela execução do Projeto. 


\section{REFERÊNCIAS}

Abo-Shehada M.N. \& Abu-Halaweh M.M. 2010. Flock-level seroprevalence of, and risk factors for, Neospora caninum among sheep and goats in northern Jordan. Prev. Vet. Med. 93:25-32.

Aguiar D.M., Chiebao D.P., Rodrigues A.A.R., Cavalcante G.T., Labruna M.B. \& Gennari S.M. 2004. Prevalência de anticorpos anti-Neospora caninum em ovinos do Município de Monte Negro, Amazônia Ocidental Brasileira. Arqs Inst. Biológico, São Paulo, 71(Supl.):277

Aiello S.E. 2001. Manual Merck de Veterinária. 8a ed. Roca, São Paulo. $1861 p$.

Al-Majali A.M., Jawasreh K.I., Talafha H.A. \& Talafha A.Q. 2008. Neosporosis in sheep and different breeds of goats from Southern Jordan: prevalence and risk factors analysis. Am. J. Anim. Vet. Sci. 3(2):47-52.

Araújo A.C., Guimarães M.F., Machado D.M.R., Freire D.P., Labruna M.B., Pena H.F.J. \& Horta M.C. 2014. Toxoplasma gondii e Neospora caninum em ovinos, caprinos, cães e gatos, Serra das Confusões, Piauí. Anais 18o Congresso Brasileiro de Parasitologia Veterinária, CBPV, Gramado. (Resumo) Disponível em <http://www.cbpv.org.br/congressos/parasitologia_2014_anais_online/trabalhos/trabalho_1603.html> Acesso em 4 nov.2015.

Camargo M.E. 1974. Improved technique of indirect immunofluorescence for serological diagnosis of toxoplasmosis. Revta Inst. Med. Trop. São Paulo 6(3):117-118.

Corbelline L.G., Smith D.R., Pescador C.A., Schmitz M., Correa A., Steffen D.J. \& Driemerier D. 2006. Herd-level risk factors for Neospora caninum seroprevalence in dairy farms of southern Brazil. Prev. Vet. Med. 74:130141.

D’Alencar C.E., Magalhães V.C.S., Barros S.L.B. \& Munhoz A.D. 2011. Neospora caninum: inquérito soro-epidemiológico no rebanho ovino do município de Tobias Barreto, Sergipe, Brasil. J. CRMV/SE 25:8.

Dubey J.P. \& Acland H.N. 1992. Neospora caninum (Apicomplexa) in a still borne goat. J. Parasitol. 78(3):532-534.

Dubey J.P. \& Lindsay D.S. 1996. A review of Neospora caninum and neosporosis. Vet. Parasitol. 67:1-59.

Faria E., Cavalcanti E., Madeiros E., Pinheiro-Júnior J., Azevedo S., Athayde A. \& Mota R. 2010. Risk factors associated with Neospora caninum seropositivity in sheep from the State of Alagoas, in the Northeast Region of Brazil. J. Parasitol. 96:197-199.

Faria E.B., Gennari S.M., Pena H.F.J., Athayde A.C.R., Silva M.L.C.R. \& Azevedo S.S. 2007. Prevalence of anti-Toxoplasma gondii and anti-Neospora caninum antibodies in goats slaughtered in the public slaughterhouse of Patos city, Paraíba State, Northeast Region of Brazil. Vet. Parasitol. 149:126-129.

Figliuolo L.P., Kasai N., Ragozo A.M., De Paula V.S., Dias R.A., Souza S.L. \& Gennari S.M. 2004. Prevalence of anti-Toxoplasma gondii and anti-Neospora caninum antibodies in sheep from São Paulo State, Brazil. Vet. Parasitol. 123:161-166.

Forar A.L., Gay J.M. \& Hancock D.D. 1995. The frequency of endemic fetal loss in dairy cattle: a review. Theriogenology 43:989-1000.

Gondim L.F.P., McAlluister M.M. \& Gao L. 2005. Effects of host maturity and prior exposure history on the production of Neospora caninum oocysts by dogs. Vet. Parasitol. 134:33-39.

Hosmer D. \& Lemeshow S. 1989. Applied Logistic Regression: a Wiley-Interscience Publication, John Wiley and Sons Inc., New York, NY. 307p.

IBGE 2013. Dados Pecuários de Sergipe. Instituto Brasileiro de Geografia e Estatística. Disponível em <http://www.ibge.gov.br/estadosat/perfil. php?sigla=se\#> Acesso em 19 set. 2015.

IBGE 2014. Bases Cartográficas. Instituto Brasileiro de Geografia e Estatística. Disponível em <http://geoftp.ibge.gov.br/organizacao_do_territorio/malhas_territoriais/malhas_municipais/municipio_2014/SE/> Acesso em 20 jun. 2016.

IBGE 2015. Dados Epidemiológicos de Sergipe. Instituto Brasileiro de Geografia e Estatística. Disponível em <http://www.ibge.gov.br/estadosat/perfil.php?sigla=se\#> Acesso em 19 set. 2015.

Langoni H., Greca Júnior H., Guimarães F.F., Ullmann L.S., Gaio F.C., Ueha- ra R.S., Rosa E.P., Amorim R.M. \& Da Silva R.C. 2010. Serological profile of Toxoplasma gondii at Neospora caninum infection in comercial sheep from São Paulo State, Brazil. Vet. Parasitol. 177:50-54.

Machado G.P., KIkuti M., Langoni H. \& Paes A.C. 2011. Seroprevalence and risk factors associated with neosporosis in sheep and dogs from farms. Vet. Parasitol. 182:356-358.

Maley S.W., Thomson K.M., Bos H.J. \& Buxton D. 1997. Serological diagnosis of toxoplasmosis in sheep following vaccination and challenge. Vet. Rec. 140(21):558-559.

Moraes L.M., Raimundo J.M., Guimarães A., Santos H.A., Macedo Junior G.D.E., Massard C.L., Machado R.Z. \& Baldani C.D. 2011. Occurrence of anti-Neospora caninum and anti-Toxoplasma gondii IgG antibodies in goats and sheep in western Maranhão, Brazil. Revta Bras. Parasitol. Vet. 20:312-317.

Moura A.B., Güths M.F., Farias J.A., Souza A.P., Sartor A.A. \& Quadros R.M. 2014. Neospora caninum seroprevalence and risk factors for ewes from Santa Catarina Plateau, Brazil. Semina, Ciênc. Agrárias 35(5):25912600.

Mugridge N.B., Morrison D.A., Heckeroth A.R., Johnson A.M. \& Tenter A.M. 1999. Phylogenetic analysis based on full-length large subunit ribosomal RNA gene sequence comparison reveals that Neospora caninum is more closely related to Hammondia heydorni than to Toxoplasma gondii. Int. J. Parasitol. 29:1545-1556.

Munhóz K.F., Neto M.L., Santos S.M.A., Garcia J.L., Júnior J.S.G., Vidotto O., Headley S.A. \& Yamamura M.H. 2010. Occurrence of anti-Neospora caninum antibodies in sheep from farms located in northern Parana, Brazil. Semina, Ciênc. Agrárias 31(4):1031-1040.

Oshiro L.M., Barros J.C., Grecco B., Gonçalves K.N. \& Andreotti R. 2008. Avaliação sorológica para Neospora caninum em fêmeas de um rebanho ovino de cria em Campo Grande, Mato Grosso do Sul. Anais 15 Congresso Brasileiro de Parasitologia Veterinária, Curitiba, PR. Colégio Brasileiro de Parasitologia Veterinária, p.422. (Resumo) Disponível em <http:// www.bdpa.cnptia.embrapa.br/consulta/marc?id=327032> Acesso em 3 nov. 2015.

Otero A.R.S., Uzêda R.S., Jesus E.E.V., Pinheiro A.M. \& Almeida M.A.O. 2005. Ocorrência de anticorpos IgG anti-Neospora caninum em rebanho de ovinos no Estado da Bahia. Anais 1ํo Fórum Brasileiro de Estudos sobre Neospora caninum, São Paulo, SP. Colégio Brasileiro de Parasitologia Veterinária. (CDROM)

Paiz L.M., Silva R.C., Menozzi B.D. \& Langoni H. 2015. Antibodies to Neospora caninum in sheep from slaughterhouses in the state of São Paulo, Brazil. Braz. J. Vet. Parasitol. 24(1):95-100.

Pappen F., Cunha N.A.F., Lucas A., Rickes E., Farias N.A. \& Gennari S.M. 2008. Prevalência de anticorpos anti-Neospora caninum em ovinos da região sul do Estado do Rio Grande do Sul. Anais 15o Congresso Brasileiro de Parasitologia Veterinária, Curitiba, PR. Colégio Brasileiro de Parasitologia Veterinária, p.333.

Pinto A.P., Bacha F.B., Santos B.S., Driemeier D., Antoniassi N.A.B., Ribas N.L.K.S. \& Lemos R.A.A. 2012. Sheep abortion associated with Neospora caninum in Mato Grosso do Sul, Brazil. Pesq. Vet. Bras. 32(8):739-742.

Rizzo H., Gregory L., Beraldi F. \& Villalobos E.C.M. 2011. Análise de fator de risco e avalição clínica de ovinos com histórico de distúrbios reprodutivos pertencentes à criatórios do estado de São Paulo, infectados por $\mathrm{Ne}$ ospora caninum e Toxoplasma gondii. Vet. Zootec. 18(4)Supl.3:908-911.

Rocha D.S., Guimarães L.A., Bezerra R.A., Mendonça C.E.D., Dorea T.G., Munhoz A.D. \& Albuquerque G.R. 2014. Seroprevalence and factors associated with Neospora caninum infection in sheep from southastern Bahia, Brazil. Revta Bras. Med. Vet. 36(4):443-447.

Roitt I.M., Brostoff J. \& Male D.K. 1999. Imunologia. 5ª ed. Helvética, São Paulo. 500p.

Romanelli P.R., Freire R.L., Vidotto O., Marana E.R.M., Ogawa L., De Paula V.S.O., Garcia J.L. \& Navarro I.T. 2007. Prevalence of Neospora caninum and Toxoplasma gondii in sheep and dogs from Guarapuava farms, Paraná State, Brazil. Res. Vet. Sci. 82:202-207.

Rosa L.D., Moura A.B., Güths M.F., Bellato V., Sartor A.A. \& Souza A.P. 2011. Prevalência e fatores de risco para infecção por Neospora caninum em 
ovinos no município de Lages, Santa Catarina, Brasil. Revta Ciênc. Agrovet. 10(2):127-137.

Rossi G.F., Cabral D.D., Ribeiro D.P., Pajuaba A.C.A.M., Corrêa R.R., Moreira R.Q., Mineo T.W.P., Mineo J.R. \& Silva D.A.O. 2011. Evaluation of Toxoplasma gondii and Neospora caninum infections in sheep from Uberlândia, Minas Gerais State, Brazil, by different serological methods. Vet. Parasitol. 175:252-259.

Salaberry S.R.S., Okuda L.H., Nassar A.F.C., De Castro J.R. \& Lima-Ribeiro A.M.C. 2010. Prevalence of Neospora caninum antibodies in sheep flocks of Uberlândia county, MG. Revta Bras. Parasitol. Vet. 19(3):148-151.

Santos G.B., De Sousa I.F., Brito C.O., Santos V.S., Barbosa R.J. \& Soares C. 2014. Estudo bioclimático das regiões litorânea, agreste e semiárida do estado de Sergipe para a avicultura de corte e postura. Ciência Rural 44(1):123-128.

Seagri 2015. Secretaria de Estado da Agricultura e do Desenvolvimento Rural. Pecuária Sergipana. Disponível em <http://www.sagri.se.gov.br/ modules/tinyd0/index.php?id=49> Acesso em 19 set. 2015.

Silva A.F., Cosendey R.I.J., Zandonadi F.B., Oliveira F.C.R., Lilenbaum W., Martins G., Venturi S.S. \& Ferreira A.M.R. 2011. Frequence of anti-Neospora caninum antibodies in ovines destined to clandestine slaughter in Rio de Janeiro. Revta UFRRJ, Ciência da Vida 31:27-31.

Soares H.S., Ahid S.M.M., Bezerra A.C.D.F., Pena H.F.J., Dias R.A. \& Gennari S.A. 2009. Prevalence of anti-Toxoplasma gondii and anti-Neospora cani- num antibodies in sheep from Mossoró, Rio Grande do Norte, Brazil. Vet. Parasitol. 160:211-214.

Souza Neto O.L., Albuquerque P.P.F., Santos A.S., Fernandes E.F.T.S., Faria E.B., Moraes E.P.B.X., Rabelo S.S.A., Silva L.G.S. \& Mota R.A. 2009. Prevalência de anticorpos IgG anti-Neospora caninum e fatores de risco associados à infecção em ovinos no município de Gravatá, Pernambuco, Brasil. Anais 9a Jornada de Ensino, Pesquisa e Extensão (JEPEX), Recife.

Tembue A.A., Ramos R.A., Sousa T.R., Albuquerque A.R., Costa A.J., Meunier I.M., Faustino M.A. \& Alves L.C. 2011. Serological survey of Neospora caninum in small ruminants from Pernambuco State, Brazil. Revta Bras. Parasitol. Vet. 20:246-248.

Thrusfield M. 1995. Veterinary Epidemiology. 2nd ed. Blackwell Scientific Publication, Oxford. 479p.

Ueno T.E., Goncalves V.S., Heinemann M.B., Dilli T.L., Akimoto B.M., Souza S.L., Gennari S.M. \& Soares R.M. 2009. Prevalence of Toxoplasma gondii and Neospora caninum infections in sheep from Federal District, central region of Brazil. Trop. Anim. Health Prod. 41:547-552.

Vogel F.S.F., Arenhart S. \& Bauermann F.V. 2006. Anticorpos anti-Neospora caninum em bovinos, ovinos e bubalinos no Estado do Rio Grande do Sul. Ciência Rural 36:1948-1951.

Wouda W., Dijkstra T., Kramer A.M.H., Van Maanen C. \& Brinkhof J.M.A. 1999. Seroepidemiological evidence for a relationship between Neospora caninum infections in dogs and cattle. Int. J. Parasitol. 29(10):1677-1682. 